\title{
Protein Synthesis Is Required for Synaptic Immunity to Depotentiation
}

\author{
Newton H. Woo ${ }^{1}$ and Peter V. Nguyen ${ }^{1,2,3}$ \\ Departments of ${ }^{1}$ Physiology and ${ }^{2}$ Psychiatry, and ${ }^{3}$ Centre for Neuroscience, University of Alberta School of Medicine, Edmonton, Alberta, T6G 2H7, Canada
}

De novo protein synthesis and transcription are necessary for the expression of long-lasting synaptic potentiation [long-term potentiation (LTP)] in hippocampal area CA1 and for the consolidation of long-term memory. The stability of LTP and its longevity require macromolecular synthesis at later stages, but a specific role for early protein synthesis has not been identified. Using electrophysiological recording methods in mouse hippocampal slices, we show that multiple trains of high-frequency stimulation provide immediate synaptic immunity to depotentiation. This immunity to depotentiation is dependent on the amount of synaptic stimulation used to induce LTP, it is input specific, and it is prevented by inhibitors of protein synthesis. We propose that local translation mediates input-specific synaptic immunity against depotentiation. We also present evidence suggesting that, in addition to translation, products of transcription can provide cell-wide immunity to depotentiation via heterosynaptic transfer of synaptic immunity between distinct pathways in area CA1. Protein synthesis and transcription may importantly regulate long-term storage of information by conferring synaptic immunity to depotentiation at previously potentiated synapses.

Key words: synaptic plasticity; long-term potentiation (LTP); depotentiation; protein synthesis; hippocampus; synaptic tagging; synaptic immunity.

\section{Introduction}

Synaptic efficacy in the hippocampus can be rapidly modified by imposed synaptic activity (for review, see Madison et al., 1991; Hawkins et al., 1993; Bear and Abraham, 1996). Hippocampal synapses can express either a persistent enhancement [long-term potentiation (LTP)] or reduction [long-term depression (LTD)] of synaptic transmission (Bliss and Lomo, 1973; Dudek and Bear, 1992; Abraham et al., 2002). LTP and LTD may critically regulate long-term information storage in the mammalian brain (Bliss and Collingridge, 1993; Moser et al., 1998; Martin et al., 2000; Brun et al., 2001).

Hippocampal LTP, which can be elicited by high-frequency stimulation (HFS), is sensitive to activity-induced reversal, or depotentiation (DPT), during a short time interval immediately after LTP induction (Barrioneuvo et al., 1980; Staubli and Lynch, 1990; Fujii et al., 1991). Low-frequency stimulation (LFS) induces DPT at previously potentiated synapses in vitro (Fujii et al., 1991; Bashir and Collingridge, 1994; Huang et al., 1999) and in vivo (Barrionuevo et al., 1980; Staubli and Lynch, 1990). DPT may keep synaptic strength within a dynamic operating range such that synaptic efficacy can remain modifiable in response to electrical activity. Although several studies have extensively characterized DPT, the factors that protect potentiated synapses from DPT have not been examined previously.

Received Sept. 20, 2002; revised Nov. 19, 2002; accepted Nov. 19, 2002.

This research was funded by grants to P.V.N. from the Alberta Heritage Foundation for Medical Research (AHFMR), the Medical Research Council (MRC) of Canada, and the Canadian Neurotrauma Research Program (Alberta Paraplegic Foundation). N.H.W. holds a postgraduate scholarship from the Natural Sciences and Engineering Research Council of Canada and a studentship from AHFMR. P.N. is a Scholar of the AHFMR and the MRC. We thank A. E. Murphy for technical assistance with imaging and photography.

Correspondence should be addressed to Peter Nguyen, Department of Physiology, University of Alberta, Medical Sciences Building, Edmonton, Alberta, T6G 2H7, Canada. E-mail: peter.nguyen@ualberta.ca.

Copyright $\odot 2003$ Society for Neuroscience $\quad 0270-6474 / 03 / 231125-08 \$ 15.00 / 0$
Some evidence that susceptibility to DPT can be altered comes from a study that showed that multiple trains of HFS induce a form of LTP that is resistant to DPT (Woo and Nguyen, 2002). In addition, genetic overexpression of one specific transcription factor [cAMP response element-binding protein (CREB)] in transgenic mice can convert decremental synaptic potentiation into a more enduring form of LTP that is protein synthesis dependent and resistant to DPT (Barco et al., 2002). In the present study, we examined the molecular mechanisms that critically regulate the susceptibility of synapses to DPT. By using standard electrophysiological techniques to examine LTP and DPT in wild-type mouse hippocampal slices, we report that synaptic immunity to DPT depends critically on the amount of imposed synaptic stimulation. We show that synaptic immunity to DPT is induced rapidly and requires protein synthesis and transcription and that the signals that are critical for establishing this synaptic immunity may originate locally at synapses or at the soma. We propose that the cellular site of macromolecular synthesis determines whether synaptic immunity to DPT is input specific or cell wide.

\section{Materials and Methods}

Animals. Female C57BL/6 mice, aged 8-12 weeks (Charles River, Montreal, Canada) were used for all experiments. Animals were housed at the University of Alberta using guidelines approved by the Canadian Council on Animal Care.

Electrophysiology. Transverse hippocampal slices (400 $\mu \mathrm{m}$ thickness) were prepared from C57BL/6 mice as described in Nguyen and Kandel (1997). Slices were maintained in an interface chamber at $28^{\circ} \mathrm{C}$ and were perfused $(1 \mathrm{ml} / \mathrm{min}$ ) with artificial CSF (ACSF) composed of (in $\mathrm{mm}$ ): $124 \mathrm{NaCl}, 4.4 \mathrm{KCl}, 1.3 \mathrm{MgSO}_{4}, 1.0 \mathrm{NaH}_{2} \mathrm{PO}_{4}, 26.2 \mathrm{NaHCO}_{3}, 2.5 \mathrm{CaCl}_{2}$, 10 glucose, aerated with $95 \% \mathrm{O}_{2}$ and $5 \% \mathrm{CO}_{2}$. Extracellular field EPSPs (fEPSPs) were recorded with a glass microelectrode filled with ACSF (resistances: 2-3 M $\Omega$ ) and positioned in stratum radiatum of area CA1. A bipolar nickel-chromium electrode was used to elicit fEPSPs by stimulating the Schaffer collateral-commissural fibers. Stimulation intensity 
(0.08 msec pulse duration) was adjusted to evoke fEPSP amplitudes that were $40 \%$ of maximal size, and fEPSPs were elicited at the rate of once per minute at this "test" stimulation intensity.

For two-pathway experiments, a second independent pathway within stratum radiatum was monitored by placing a second bipolar stimulating electrode in this region. Placement of S2 was adjusted so that pairedpulse facilitation (PPF) was not observed when stimulating electrodes S1 and S2 were sequentially activated by paired S1-S2 stimulus pulses spaced $75 \mathrm{msec}$ apart.

For experiments on isolated CA1 dendrites, hippocampal slices were cut in ice-cold ACSF ( $\mathrm{NaCl}$ was replaced by equimolar sucrose, and $\mathrm{CaCl}_{2}$ was replaced by $\mathrm{MgCl}_{2}$ ), after which two incisions were made under a dissecting microscope. One cut was applied just below the cell body layer of area CA1, and another incision was applied in area CA3 (see Fig. $3 A$ ). Slices were then perfused with normal ACSF and allowed to recover in an interface chamber for at least $2 \mathrm{hr}$ before recordings commenced. Slices were used if the following criteria were met: (1) absence of a population spike when the recording electrode was placed at the cell body layer and strong stimulation was applied in stratum radiatum below the cut, and (2) absence of an fEPSP in stratum radiatum below the incision when stimulation was applied at the basilar dendrites in stratum oriens. Bright-field digital images ( $10 \times$ magnification) were captured using a SPOT Digital Microscope (Carsen Group, Toronto, Canada) mounted on an Olympus BX40 microscope.

LTP was induced by applying either two trains of HFS $(100 \mathrm{~Hz}, 1 \mathrm{sec}$ duration at test strength) or four trains of HFS $(100 \mathrm{~Hz}, 1 \mathrm{sec}$ duration at test strength) spaced $20 \mathrm{sec}$ apart. DPT was induced by applying LFS consisting of $5 \mathrm{~Hz}$ for $3 \mathrm{~min}$.

Two different translational inhibitors, anisomycin (25 $\mu \mathrm{M}$; Research Biochemicals, Natick, MA) and emetine (20 $\mu \mathrm{M}$; Sigma, St. Louis, MO), were prepared as concentrated stock solutions in DMSO and distilled water, respectively. The transcriptional inhibitor, actinomycin D ( $25 \mu \mathrm{M}$; Sigma), was prepared in DMSO. Each drug was then diluted in ACSF to the desired final concentration and was bath applied during baseline fEPSP acquisition and LFS for a total period of $30 \mathrm{~min}$. The final concentration of DMSO did not exceed $0.01 \%$; at this concentration DMSO did not affect basal synaptic transmission or LTP (data not shown). Drug experiments were interleaved with drug-free controls.

Data analysis. The initial slope of the fEPSP was measured as an index of synaptic strength. Average "baseline" slope values were acquired over a period of $20 \mathrm{~min}$ before $100 \mathrm{~Hz}$ HFS. Student's $t$ test (two groups), or an ANOVA with a Tukey-Kramer post-test (three or more groups), was used for statistical comparisons of mean fEPSP slopes, with a significance level of $p<0.05$. All values shown are mean \pm SE (SEM), with $n=$ number of slices.

\section{Results \\ Four-train stimulation induces LTP that is resistant to depotentiation}

Several distinct forms of LTP, elicited by various stimulation protocols, require protein synthesis for their expression (Krug et al., 1984; Stanton and Sarvey, 1984; Frey et al., 1988; Nguyen et al., 1994; Scharf et al., 2002). As an initial step toward defining the roles of activity, transcription, and translation in mediating synaptic immunity to DPT, we tested the protein synthesis dependence of LTP elicited by two trains versus four trains of $100 \mathrm{~Hz}$ HFS. We bath applied anisomycin, an inhibitor of translation, to mouse hippocampal slices at a concentration that inhibits $>85 \%$ of protein synthesis (Frey et al., 1988). We found that LTP elicited by two trains of HFS (20 sec interburst spacing) was unaffected by anisomycin (Fig. $1 \mathrm{~A}$ ). The mean fEPSP slopes measured $5 \mathrm{~min}, 1$ $\mathrm{hr}$, and $2 \mathrm{hr}$ after LTP induction were $263 \pm 19,193 \pm 10$, and $159 \pm 10 \%$, respectively (Fig. $1 \mathrm{~A}$, squares). Corresponding slope values in drug-free slices were $229 \pm 14,181 \pm 10$, and $158 \pm$ $17 \%$ (Fig. $1 \mathrm{~A}$, circles), and these were not significantly different ( $p>0.05$ at all time points) from anisomycin-treated values. In contrast, when two additional trains of HFS (i.e., $4 \times 100 \mathrm{~Hz}$ ) were added to our stimulation regimen (with the interburst interval kept the same, at $20 \mathrm{sec}$ duration), slices that received anisomycin showed decaying LTP (Fig. $1 B$, squares). This stronger tetanus protocol elicited stable LTP in control drug-free slices, with mean fEPSP slope values of $307 \pm 25,216 \pm 21$, and $222 \pm$ $16 \%$, measured $5 \mathrm{~min}, 1 \mathrm{hr}$, and $2 \mathrm{hr}$ after HFS, respectively. Corresponding slope values in anisomycin-treated slices were $238 \pm 27,153 \pm 27$, and $101 \pm 17 \%$, with a significant difference seen beginning at $30 \mathrm{~min}$ after HFS (Fig. $1 B$, squares) $(p<0.05)$. When a second independent pathway in slices was monitored in the presence of anisomycin, no effect was observed on baseline (Fig. $1 \mathrm{~B}$, triangles). It should be noted that the two-train tetanus protocol elicited significantly less LTP than four trains of $100 \mathrm{~Hz}$ (assessed $5 \mathrm{~min}$ and $2 \mathrm{hr}$ after stimulation) (Fig. 1A,B) $(p<$ $0.05)$. These findings show that in the transition from two to four trains, the addition of two trains of HFS can induce different forms of LTP that differentially engage protein synthesis, consistent with previous studies (Huang and Kandel, 1994; Winder et al., 1998).

We next asked whether this same increase in the amount of stimulation can critically change the susceptibility of potentiated synapses to DPT. To induce DPT, we used an LFS protocol consisting of $5 \mathrm{~Hz}$ stimulation for $3 \mathrm{~min}$. LFS alone produced only a transient depression of fEPSP slopes that subsequently recovered to pre-LFS values within $10 \mathrm{~min}$. (Fig. 1C). However, LFS after induction of $2 \times 100 \mathrm{~Hz}$ LTP reversed potentiated fEPSP slopes back to pre-LTP baseline values (Fig. $1 D$, filled squares), which is consistent with earlier studies (Barrioneuvo et al., 1980; Fujii et al., 1991). Mean fEPSP slopes measured immediately after HFS and $50 \mathrm{~min}$ after LFS, were $343 \pm 25$ and $102 \pm 18 \%$, respectively. The corresponding mean fEPSP slopes in control slices receiving only HFS were $354 \pm 33$ and $166 \pm 12 \%$ (Fig. 1D, open squares), with the latter value being significantly higher than the mean value measured from slices that received HFS followed by LFS $(p<0.01)$ (Fig. $1 D$, filled squares).

In contrast, adding two additional trains of HFS blocked the expression of DPT induced by LFS (Fig. $1 E$, filled circles). Four trains of $100 \mathrm{~Hz}$ stimulation, spaced $20 \mathrm{sec}$ apart, induced stable potentiation with mean fEPSP slope values of $326 \pm 21,267 \pm 18$, and $176 \pm 19 \%$, measured immediately, $5 \mathrm{~min}$, and $50 \mathrm{~min}$ after HFS, respectively (Fig. $1 E$, open squares). Application of $5 \mathrm{~Hz}$ LFS, 5 min after LTP induction, initially depressed fEPSP slope values that subsequently recovered to previously potentiated values (Fig. 1 E, filled circles): corresponding mean values were $380 \pm$ 43, $298 \pm 33$, and $167 \pm 17 \%$, respectively.

Because the number of stimulation pulses was doubled during four trains of HFS (Fig. $1 B$ ), a stronger LFS protocol may be required to elicit subsequent DPT. Thus, an extended LFS protocol consisting of $5 \mathrm{~Hz}$ stimulation for a period of $6 \mathrm{~min}$ was applied 2 min after four-train LTP. Similar to the 3 min LFS protocol, an initial depression followed by recovery to potentiated values was observed (Fig. $1 E$, filled squares). Mean fEPSP slope values for the extended LFS group were $327 \pm 41$ and $182 \pm 31 \%$, measured immediately and 50 min after HFS, respectively. An ANOVA did not reveal a difference between the two LFS groups and the control group, which received only HFS $(p>0.5)$.

We also reduced the interval between LTP induction and LFS application by decreasing the time interval between successive trains during HFS, because induction of DPT is time dependent (O'Dell and Kandel, 1994; Chen et al., 2001). Four trains of 100 $\mathrm{Hz}$ stimulation, using $3 \mathrm{sec}$ interburst intervals, elicited robust potentiation with mean fEPSP slope values of $354 \pm 42,307 \pm 25$, and $224 \pm 18 \%$, measured immediately, $5 \mathrm{~min}$, and $50 \mathrm{~min}$ after 

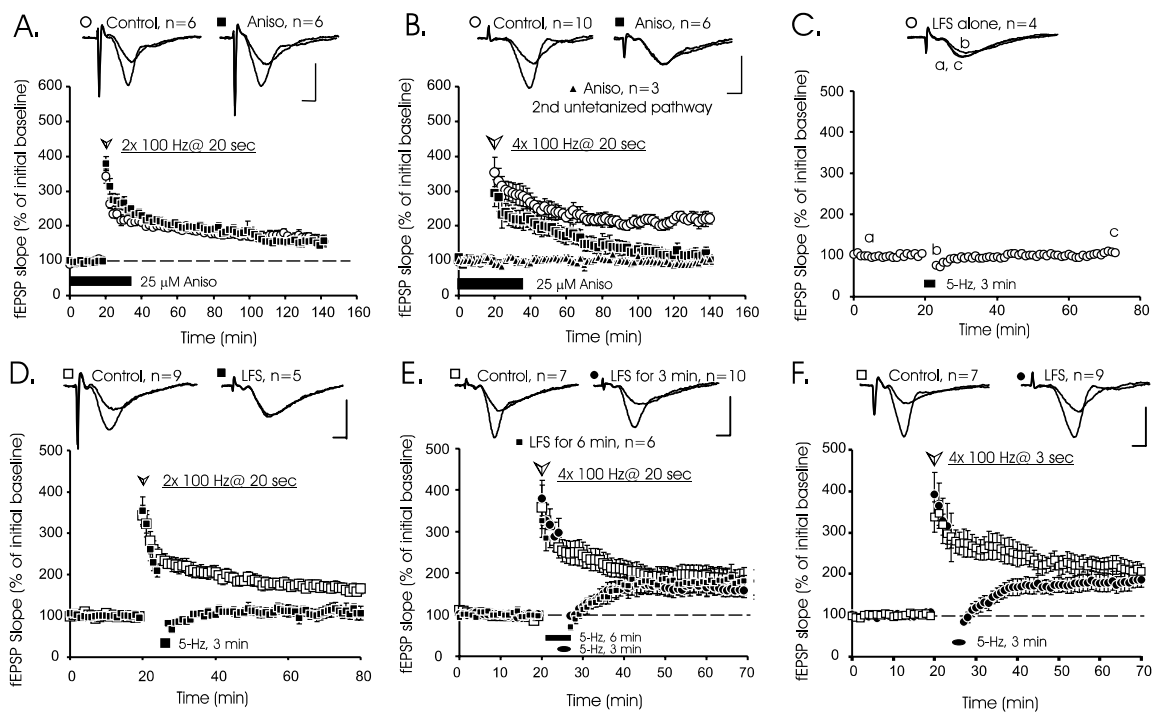

Figure 1. Synaptic immunity to DPT is activity dependent. A, Application of anisomycin did not significantly alter two-train LTP (squares). Sample fEPSP traces were recorded 5 min before HFS and $2 \mathrm{hr}$ after HFS. B, Four-train LTP in anisomycin slowly decayed to baseline within $100 \mathrm{~min}$ (squares). Sample traces taken at $5 \mathrm{~min}$ before HFS and $2 \mathrm{hr}$ after HFS. C, LFS alone transiently depressed fEPSPs, which recovered back to pre-LFS slope values. D, LFS given 5 min after two trains of HFS persistently erased LTP ( filled squares), whereas fEPSPs in slices that received HFS without LFS remained potentiated (open squares). E, In contrast, when LFS was applied after four trains of HFS, spaced 20 sec apart, persistent DPT was not observed ( filled circles). When LFS was applied for 6 min, four-train LTP was still not persistently erased ( filled squares). F, Similarly, when the spacing between successive trains of HFS was compressed to $3 \mathrm{sec}$, no persistent DPT was observed after LFS (circles). All sample traces from DPT experiments were taken at $5 \mathrm{~min}$ before HFS and $40 \mathrm{~min}$ after LFS. Calibration: $5 \mathrm{mV}, 2 \mathrm{msec}$.

HFS, respectively (Fig. $1 F$, squares). When subsequent LFS was applied ( $5 \mathrm{~min}$ after this compressed HFS), an initial depression followed by a recovery of fEPSPs to potentiated values was observed (Fig. $1 F$, circles). The corresponding values in slices that received LFS were $393 \pm 53,288 \pm 58$, and $187 \pm 20 \%$, respectively ( $p>0.1$, at all time points indicated).

In summary, these data demonstrate that a close correspondence exists between the amount of stimulation used to induce LTP and the susceptibility of LTP to DPT. Two trains of HFS elicit protein synthesis-independent LTP that is reversed or depotentiated by subsequent LFS. In contrast, four trains of HFS induce protein synthesis-dependent LTP that is immune to DPT.

\section{Local protein synthesis, but not transcription, confers homosynaptic immunity to DPT}

Because no difference was detected between anisomycin-treated and control slices within $30 \mathrm{~min}$ after four-train stimulation (Fig. $1 B$ ), protein synthesis may not play a role in the early stages. However, some studies have reported that protein synthesis can be engaged very early after tetanization (Otani et al., 1989; Ouyang et al., 1999). Thus, we asked whether early protein synthesis, which may not contribute to early LTP, may nonetheless be involved in regulating the susceptibility of synapses to DPT.

To identify a critical requirement for early protein synthesis in mediating synaptic immunity to DPT, we bath applied two translational inhibitors, anisomycin or emetine, to hippocampal slices. Both anisomycin and emetine, at lower concentrations than those used here, blocked protein synthesis by $>80 \%$ in hippocampal slices [for emetine data see Stanton and Sarvey (1984); for anisomycin data see Frey et al. (1988)]. We found that either inhibitor permitted DPT, which was not normally seen after four trains of HFS (Fig. 2A,B). In slices that did not receive LFS, mean fEPSP slope values 40 min after HFS were $165 \pm 17$ and $155 \pm 5 \%$ in the presence of anisomycin and emetine, respectively. In con- trast, when LFS was applied 5 min after LTP induction in the presence of these inhibitors, initially depressed fEPSP slopes recovered only to pre-HFS baseline values (Fig. $2 A, B$, circles). Mean fEPSP slope values seen after LFS in anisomycin- and emetine-treated slices were $113 \pm 10$ and $99 \pm 6 \%$, respectively $(p<0.02$ when compared with controls without LFS).

In contrast to the persistent DPT observed with these translational inhibitors, application of a transcriptional inhibitor, actinomycin-D, failed to facilitate DPT. At the concentration used here, actinomycin-D has been shown to block transcription by $>70 \%$ in hippocampal slices (Nguyen et al., 1994). After LFS, initially depressed fEPSP slopes gradually increased to potentiated levels similar to control slices receiving only HFS (Fig. $2 C$, circles). The mean fEPSP slope value measured $40 \mathrm{~min}$ after HFS was $148 \pm$ $17 \%$ ( $p>0.2$ for comparison with a mean value of $168 \pm 21 \%$ in slices that received LFS after HFS). Thus, homosynaptic immunity of four-train LTP to DPT was dependent on protein synthesis, but it did not require transcription (Fig. 2D summarizes these data).

Because four trains of HFS confer immediate synaptic immunity, local protein synthesis may be critical for this process. To test this idea, we recorded from slices containing isolated CA1 pyramidal cell dendrites that were created by applying two small cuts just under the cell body layers of areas CA1 and CA3 (Fig. 3A, two bold lines). A bright-field digital image of a representative cut hippocampal slice is shown in Figure $3 B$. These slices exhibited smaller maximal fEPSP amplitudes, ranging from 1 to $3 \mathrm{mV}$. When four trains of HFS were applied to these slices, robust potentiation was elicited: a mean fEPSP slope of $164 \pm 19 \%$ was measured 40 min after HFS (Fig. 3C, squares). This potentiation lasted $>40 \mathrm{~min}$, but it slowly decayed to preHFS baseline slope values within $2 \mathrm{hr}$ (data not shown). When subsequent LFS was applied to cut slices, a transient depression was observed, but fEPSPs recovered to potentiated values with a mean value of $165 \pm 19 \%$ (Fig. $3 C$, circles) $(p>0.2)$. Application of either anisomycin or emetine to these slices permitted subsequent DPT by LFS after four-train LTP (Fig. 3D). The mean fEPSP slope was $175 \pm 17 \%$ in cut slices, measured 40 min after HFS (Fig. 3D, open circles). In contrast, mean corresponding slope values for anisomycin-treated (Fig. 3D, filled circles) and emetine-treated (Fig. 3D, filled squares) cut slices after LFS were $89 \pm 13$ and $103 \pm 6 \%$, respectively $(p<0.01$, compared with corresponding control value). Both inhibitors of translation did not affect four-train LTP in these cut slices (data not shown). This finding, when considered alongside our translational inhibitor data in intact cells (Fig. $3 A, B$ ), suggests that local protein synthesis initiated immediately after tetanus, without previous transcription, can block DPT.

\section{Input-specific versus cell-wide synaptic immunity to DPT}

Because DPT of four-train LTP occurred only when protein synthesis was blocked, inhibition of protein synthesis by anisomycin may have altered synaptic properties. Thus, we assessed the input specificity of DPT of four-train LTP in the presence of anisomy- 

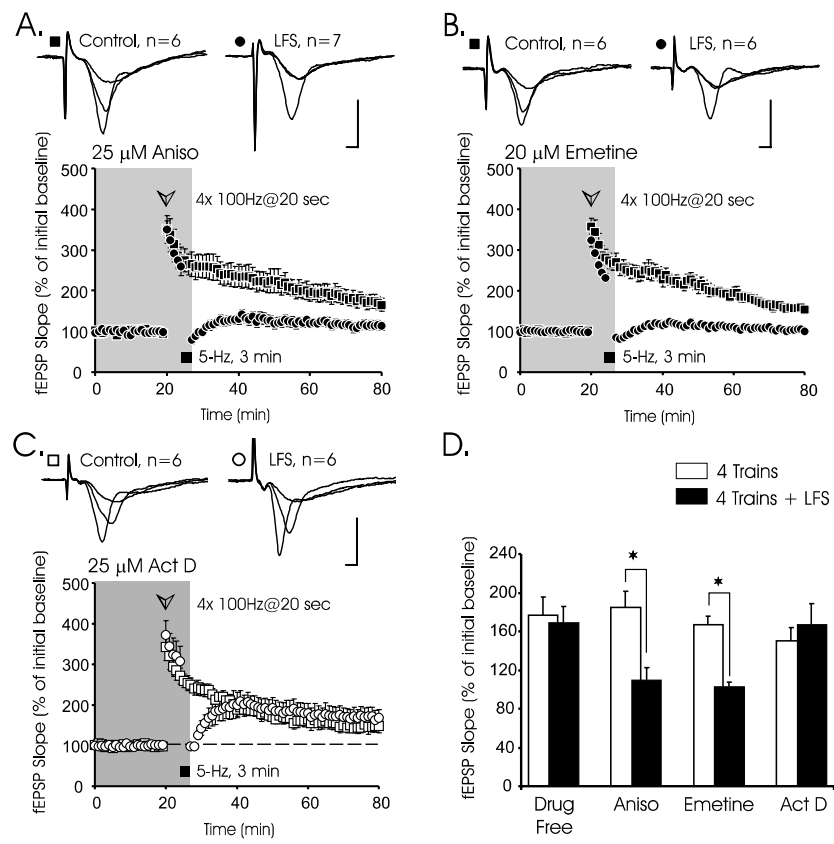

Figure 2. Protein synthesis is required to "immunize" LTP against DPT. Application of either anisomycin $(A)$ or emetine $(B)$, both inhibitors of translation, permitted persistent DPT of four-train LTP (circles). C, Application of a transcriptional inhibitor, actinomycin-D, did not block immunity to DPT, and no persistent DPT was observed (circles). Sample sweeps in A-C were taken 5 min before HFS, immediately after HFS, and 40 min after LFS. Calibration: $5 \mathrm{mV}, 2 \mathrm{msec}$. $D$, Summary histogram for these experiments.

cin. A previous study characterizing DPT in hippocampal slices reported that reversal of LTP was input specific (Huang et al., 2001).

We stimulated two independent pathways in stratum radiatum of area CA1, in anisomycin-treated slices. One pathway (S1) received HFS followed 5 min later by LFS, whereas a second pathway (S2) received only HFS. Figure $4 A$ shows that application of LFS ( 5 min after HFS) to S1 elicited persistent DPT only in S1. Pathway S2, which was transiently depressed, remained potentiated, with a mean fEPSP slope value of $175 \pm 23 \%$ measured at $60 \mathrm{~min}$ after HFS. This was significantly higher than the corresponding value of $90 \pm 10 \%(p<0.01)$ measured in S1. Interestingly, fEPSP slopes in S2 were transiently reduced immediately after LFS in S1, thereby revealing a short-lasting heterosynaptic effect of $5 \mathrm{~Hz}$ stimulation. This effect was unlikely the result of nonspecific effects of anisomycin or partial overlap of activated synapses in the two pathways, because no heterosynaptic PPF was observed between S1 and S2, whereas strong homosynaptic PPF was seen in these pathways (data not shown). In addition, induction of LTP in one pathway produced input-specific changes without modifying transmission in an independent pathway (Fig. $4 B, C)$. It was demonstrated previously that synaptic activity affected a second independent pathway only if that pathway experienced previous plasticity (Muller et al., 1995); this may explain the present short-lasting reduction in fEPSP slopes seen in S2. These data show that DPT of four-train LTP, which occurs only when protein synthesis is inhibited, is input specific.

We next asked whether synaptic immunity can be transferred between independent pathways (i.e., whether it is heterosynaptic) by examining whether stimulation of one pathway can block DPT in an adjacent pathway by synaptic "capture" of proteins (Fig. $4 B$ ). We applied four trains of HFS to one pathway to induce protein synthesis-dependent LTP and allowed 45 min to elapse
A.
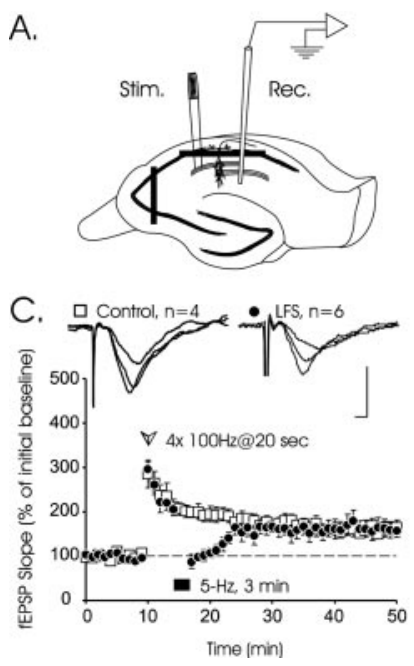

B.

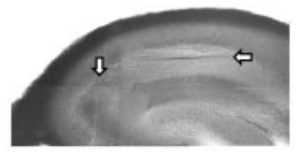

D.

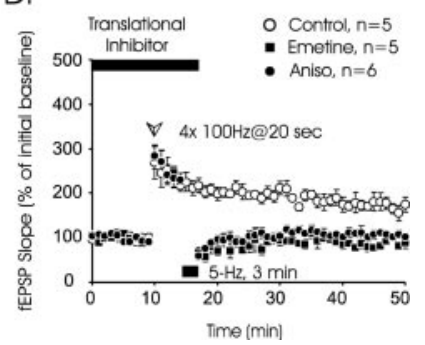

Figure 3. Local protein synthesis is required for synaptic immunity to DPT. A, Schematic diagram showing the two incisions (thick black lines) made to isolate CA1 neuropil and the positions of recording and stimulation electrodes. B, Bright-field image of a hippocampal slice after two incisions (arrows) were made to isolate CA1 neuropil ( $10 \times$ magnification). The dentate gyrus is at the bottom right edge of the photograph. C, When LFS was applied shortly after four trains of HFS in isolated CA1 pyramidal cell dendrites, transient synaptic depression was seen (circles), but fEPSP slopes recovered to potentiated levels not significantly different from those seen in cut slices that received HFS alone (squares). Traces were taken 5 min before HFS, immediately after HFS, and 30 min after LFS. Calibration: $2 \mathrm{mV}, 2 \mathrm{msec}$. D, Both anisomycin ( filled circles) and emetine ( filled squares) permitted the expression of DPT after four trains of HFS in slices containing cut CA1 dendrites.

before we applied two trains of HFS to an adjacent pathway. This delay allowed macromolecular synthesis to occur, and there is evidence that such synthesis is critical for converting short- to long-lasting types of synaptic plasticity by synaptic capture (Frey and Morris, 1997; Barco et al., 2002). DPT was blocked in the S2 $(2 \times 100 \mathrm{~Hz})$ pathway if it followed induction of four-train LTP in an adjacent (S1) pathway (Fig. $4 B$ ). When LFS was applied to S2 after two-train LTP induction in S2 ( 45 min after four trains of HFS were applied to 1 1), fEPSPs were initially depressed, but they recovered to previously potentiated levels, with a mean value of $196 \pm 10 \%$ measured at $40 \mathrm{~min}$ after LFS (Fig. 4B, bottom, S2, open circles). However, when four trains of HFS were applied to S1 in the presence of bath-applied anisomycin (Fig. 4B, top, S1, black squares) and the S2 pathway was subsequently given two trains of HFS, LTP induced in the S2 pathway was persistently reversed by $5 \mathrm{~Hz}$ LFS (Fig. 4 B, bottom, S2, black circles). These results suggest that activity-induced synaptic capture of newly synthesized proteins can confer immunity to DPT. This heterosynaptic process may involve the transfer, or capture, by synaptic sites, of proteins the synthesis of which is triggered by activity at other synaptic sites.

To assess whether products of local protein synthesis are critical for heterosynaptic immunity to DPT, we applied a transcriptional inhibitor, actinomycin-D, to intact slices while monitoring two independent pathways. By inhibiting somatic transcription, we could assess the potential necessity for somatic products in mediating the transfer of immunity to DPT from one pathway (or synaptic site) to another. When transcription was inhibited by bath-applied actinomycin-D, and cell-wide translation was allowed to occur, four trains of HFS in one pathway (Fig. 4C, S1) did not elicit immunity to DPT at an adjacent pathway that received two trains of HFS (Fig. 4C, S2). Two-train LTP in this second pathway (S2) was persistently erased after previous four- 

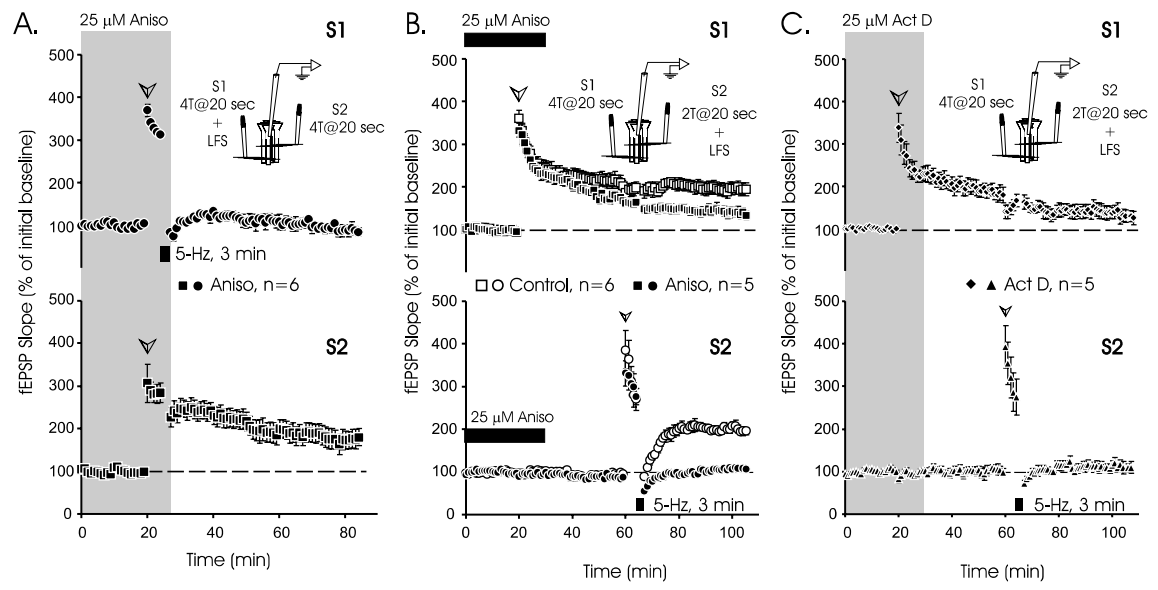

Figure 4. Input specificity, homosynaptic, and heterosynaptic properties of synaptic immunity to DPT. $A$, In the presence of anisomycin, DPT of four-train LTP is input specific. When two pathways received four trains of HFS in the presence of anisomycin, only the pathway receiving LFS 5 min after HFS (S1, circles) showed DPT, whereas the other pathway showed robust LTP (S2, squares). $B$, Synaptic immunity may be conferred by cell-wide intersynaptic transfer of newly expressed gene products. When four trains of HFS were applied to one pathway (S1, open squares), two-train LTP in a second adjacent pathway (S2, open circles) became resistant to DPT. Inhibition of protein synthesis (black symbols), by bath application of anisomycin to both $\mathrm{S1}$ and $\mathrm{S2}$, blocked heterosynaptic transfer of resistance to DPT at S2. Two-train LTP at S2 could now be erased after previous four trains of HFS priming at S1 (black circles in bottom half). C, Inhibition of transcription by actinomycin-D blocked transfer of synaptic immunity to pathway $\$ 2$ after priming by four trains of HFS in pathway $S 1$.

train LTP induction in S1. The mean fEPSP slope measured in S2 30 min after LFS was $108 \pm 9 \%$, and the corresponding value in S1 was $141 \pm 11 \%(p<0.05)$. These findings mirror our results with bath-applied anisomycin: two-train LTP in one pathway (S2) was persistently erased by LFS applied $45 \mathrm{~min}$ after four trains of HFS were given in an adjacent pathway (S1) (Fig. $4 B$, black symbols). Taken together, these results suggest that protein synthesis initiated at the soma, and not transfer of locally synthesized proteins between distinct synaptic sites, is critical for heterosynaptic transfer of immunity to DPT.

\section{Discussion}

\section{Synaptic immunity to DPT: roles of activity}

Synapses in invertebrates and vertebrates can experience longlasting alterations in their physiological strength (Hawkins et al., 1993; Huang et al., 1996; Martin et al., 2000). Certain forms of synaptic plasticity require protein synthesis and transcription (for review, see Hawkins et al., 1993; Martin et al., 2000; Steward and Schuman, 2001), and particular proteins may be synthesized at synaptic sites after changes in the electrical activity of these synapses (for review, see Steward and Schuman, 2001). An intriguing observation made in the present study is the rapid and critical modulation by activity of the reversibility of LTP. In changing from a two-train to a four-train tetanus protocol, the addition of just two trains of HFS (representing only $2 \mathrm{sec}$ of additional imposed activity) was sufficient to convert LTP from a form that was susceptible to DPT to one that was immune to DPT.

The mechanisms underlying DPT have been partially elucidated (for review, see Huang and Hsu, 2001). However, the factors that critically regulate the susceptibility of different forms of LTP to DPT have not been identified. Like memory, hippocampal LTP has several distinct temporal phases (for review, see Huang et al., 1996). A "late" phase of LTP (L-LTP) is defined by its requirement for protein synthesis and transcription. Inhibitors of either translation (Krug et al., 1984; Stanton and Sarvey, 1984; Frey et al., 1988; Scharf et al., 2002) or transcription
(Nguyen et al., 1994; Frey et al., 1996) block expression of L-LTP induced by multiple $100 \mathrm{~Hz}$ trains, without affecting a more modest form of LTP elicited by weaker stimulation (Huang and Kandel, 1994). These studies demonstrate that de novo protein synthesis is engaged at later stages to mediate the expression of L-LTP, which is in agreement with our data, but they have not identified an early role for macromolecular synthesis. Our results demonstrate an early role for protein synthesis during LTP, one that is critical for "consolidating" synaptic potentiation into a resilient state that is immune to DPT.

\section{Local dendritic protein synthesis and synaptic immunity to DPT}

Application of anisomycin or emetine, both inhibitors of translation, enabled depotentiation of four-train LTP without affecting hippocampal slice viability, the initial magnitude of LTP, or the input specificity of DPT. Many previous studies have demonstrated that protein synthesis inhibition is reversible and does not affect neuronal properties such as excitability (Stanton and Sarvey, 1984). In addition, our study shows that inhibition of protein synthesis does not affect basal transmission in hippocampal slices (Fig. $1 B$ ), which confirms many previous findings (Krug et al., 1984; Frey et al., 1988, 1996; Nguyen et al., 1994; Scharf et al., 2002).

In contrast to inhibitors of translation, actinomycin-D, an inhibitor of transcription, did not enable DPT after induction of four-train LTP. Furthermore, when we recorded from slices containing isolated CA1 neuropil, blockade of DPT was still evident, indicating that the soma is not required for homosynaptic immunity to DPT. Thus, an essential step for initiating immunity may be the translation of preexisting mRNA, as suggested by the block of synaptic immunity to DPT by translational inhibitors applied to slices containing isolated neuropil. Although we cannot exclude the possibility that local protein synthesis occurs in cells other than pyramidal cells (e.g., glia, interneurons), the most likely source of translation may be the dendrites of CA1 pyramidal neurons. Polyribosomes are present in dendritic shafts (Steward and Levy, 1982; Steward and Falk, 1986, 1991), and they can mediate local protein synthesis in isolated dendrites of hippocampal neurons (Aakalu et al., 2001). In addition, a study reported that a tetanus protocol $(4 \times 100 \mathrm{~Hz}, 30 \mathrm{sec}$ intervals $)$ similar to the one used in our present study can rapidly initiate dendritic protein synthesis in hippocampal slices (Ouyang et al., 1999). It is unlikely that axons of presynaptic CA3 neurons are the sites of local protein synthesis, because functional axonal protein synthesis has not yet been identified in the hippocampus (Torre and Steward, 1992).

Several studies suggest that dendritic protein synthesis can mediate persistent changes in synaptic efficacy (Kang and Schuman, 1996; Huber et al., 2000). Some of the dendritic molecules needed for initiating translation at local dendritic sites have been identified (Tang et al., 2002), but the activity dependence of their recruitment has not yet been clearly defined. In the present study, additional synaptic activity imposed during four-train HFS may 
have engaged translational machinery at dendrites (or at other extra-somatic sites) to elicit synaptic immunity to DPT. This may be triggered by activation of distinct calcium stores by the two different tetanus protocols. Indeed, calcium stores are narrowly tuned to different forms of LTP (Raymond and Redman, 2002). Similarly, local protein synthesis may have different calcium thresholds for its activation. Further studies are required to define the calcium-dependent processes that may regulate local protein synthesis.

Although the identities of the dendritic proteins required for synaptic immunity to DPT are unknown, our observations suggest that the candidate proteins should be upregulated rapidly and locally synthesized and that their synthesis should be activity dependent. Some candidates may include Arc, an actin-binding cytoskeletal protein (Link et al., 1995; Lyford et al., 1995; Steward et al., 1998; Ying et al., 2002), and the $\alpha$-subunit of CaMKII (Burgin et al., 1990; Ouyang et al., 1999). Another plausible mechanism by which local protein synthesis may confer synaptic immunity to DPT is through alterations of adenosine metabolism by the newly synthesized product(s). Accumulation of extracellular adenosine is required for DPT (Huang et al., 1999). Stronger stimulation protocols, such as four-train HFS, may modify adenosine metabolism to blunt the increase in extracellular adenosine elicited by subsequent LFS. Further work, involving the use of functional knock-outs of candidate proteins, is needed to assess the potential roles of specific candidate proteins in conferring synaptic immunity to DPT.

\section{Transcription and cell-wide synaptic immunity to DPT}

Independent, long-term control of physiological strength at individual synapses has been proposed to involve a synaptic "tagging" process, during which plasticity-related proteins may be sequestered at tagged synapses that had experienced activity (Frey and Morris, 1997, 1998; Martin et al., 1997). Accumulation of these proteins may convert temporary synaptic modifications into more persistent alterations. Another function of plasticity proteins that are produced by transcription may be to provide cell-wide synaptic immunity to DPT. Although transcription was not required for homosynaptic immunity to DPT, it was required for heterosynaptic transfer of synaptic immunity to DPT. Some studies have suggested that the cAMP signaling pathway can inhibit DPT (Natsuki et al., 1997; Otmakhova and Lisman, 1998). Modulators of this pathway alter cAMP-mediated transcriptional processes in hippocampal neurons (Impey et al., 1996; Matsushita et al., 2001). One important transcription factor involved in cAMP-regulated gene expression is CREB. Signals that induce LTP, such as multiple trains of HFS, can elicit CREB-mediated transcription in hippocampal neurons (Impey et al., 1996) (but also see Deisseroth et al., 1996). Expression of a constitutively active isoform of CREB in mutant mice transformed unstable LTP into long-lasting LTP that was immune to DPT (Barco et al., 2002). Consistent with these findings, we showed that induction of protein synthesis-dependent LTP in one synaptic pathway can elicit cell-wide immunity to DPT, as evident from the inhibition of DPT after two-train LTP was elicited at adjacent synaptic inputs. In our model (Fig. 5), when four trains of HFS were applied to one pathway, the end products of transcription (i.e., somatic proteins and mRNA) were sequestered at an independent pathway that became immune to DPT. Two-pathway experiments showed that transcription and protein synthesis are required for synaptic immunity. This implies that a product of local protein synthesis, which mediates immunity to DPT at a given synapse, does not pass directly from one syn-

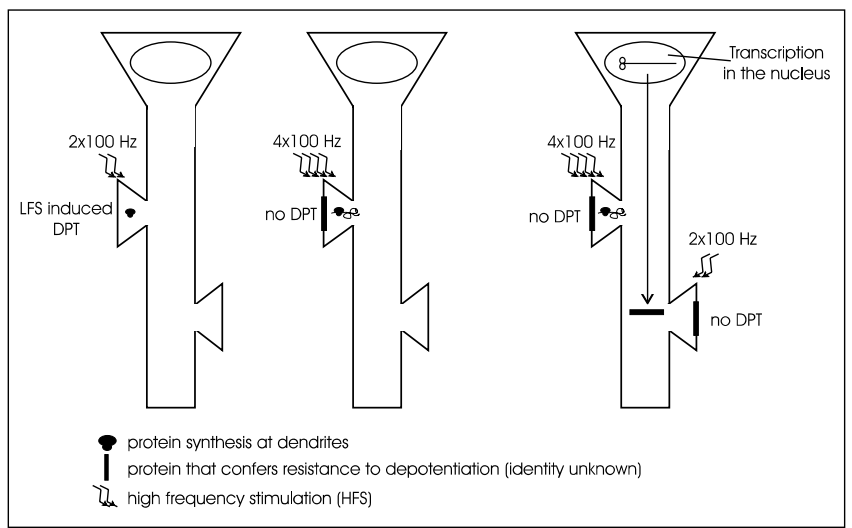

Figure 5. Schematic model of protein synthesis-dependent synaptic immunity to DPT. LTP induced by two $100 \mathrm{~Hz}$ trains can be persistently erased by DPT (left). In contrast, LTP elicited by four $100 \mathrm{~Hz}$ trains cannot be persistently erased, and this homosynaptic resistance to DPT likely requires translation at dendrites (center). Transfer of the immunity to DPT can occur between distinct synaptic sites on CA1 pyramidal neurons (right). Local protein synthesis initiated by four trains of HFS is necessary for homosynaptic immunity to DPT. However, transcription is needed for effective transfer of resistance to DPT from one input pathway to another. Thus, a molecular signaling relay may occur, so that stimulation may trigger production of somatic signals (e.g., proteins), which then confer immunity to DPT at remote synaptic sites, via sequestering of these signals at these sites.

aptic site to another. Instead, a sequential soma-to-dendrite relay, involving somatic transcription, may be needed for cellwide immunity to DPT.

\section{Synaptic immunity: potential functions in the context of LTP, learning, and memory}

Changes in synaptic efficacy may act in tandem to allow for the detection and storage of new information in neural circuits. Synaptic immunity to DPT provides activity-dependent protection of synapses against erasure of LTP. Such immunity may serve as a "high-pass filter" to allow for the expression of resilient, long-lasting types of LTP induced by repeated highfrequency patterns of activity that are also critical for eliciting translation- and transcription-dependent forms of LTP. Because the strong tetanus protocol used in this study to induce LTP has been correlated with hippocampus-dependent memory in mice (Abel et al., 1997; Miller et al., 2002), we speculate that activity-dependent synaptic immunity of LTP against DPT may be important for controlling the neural threshold for the consolidation of short-term memories into long-term memories.

\section{References}

Aakalu G, Smith WB, Nguyen N, Jiang C, Schuman EM (2001) Dynamic visualization of protein synthesis in hippocampal neurons. Neuron 30:489-502.

Abel T, Nguyen PV, Barad M, Deuel TA, Kandel ER, Bourtchouladze R (1997) Genetic demonstration of a role for PKA in the late phase of LTP and in hippocampus-based long-term memory. Cell 88:615-626.

Abraham WC, Logan B, Greenwood JM, Dragunow M (2002) Induction and experience-dependent consolidation of stable long-term potentiation lasting months in the hippocampus. J Neurosci 22:9626-9634.

Barco A, Alarcon JM, Kandel ER (2002) Expression of constitutively active CREB protein facilitates the late phase of long-term potentiation by enhancing synaptic capture. Neuron 108:689-703. 
Barrionuevo G, Schottler F, Lynch G (1980) The effects of repetitive lowfrequency stimulation on control and "potentiated" synaptic responses in the hippocampus. Life Sci 27:2385-2391.

Bashir ZI, Collingridge GL (1994) An investigation of depotentiation of long-term potentiation in the CA1 region of the hippocampus. Exp Brain Res 100:437-443.

Bear MF, Abraham WC (1996) Metaplasticity: the plasticity of synaptic plasticity. Trends Neurosci 19:126-130.

Bliss TVP, Collingridge GL (1993) A synaptic model of memory: long-term potentiation in the hippocampus. Nature 361:31-39.

Bliss TVP, Lomo T (1973) Long-lasting potentiation of synaptic transmission in the dentate area of the anaesthetized rabbit following stimulation of the perforant path. J Physiol (Lond) 232:331-356.

Brun VH, Ytterbo K, Morris RGM, Moser MB, Moser EI (2001) Retrograde amnesia for spatial memory induced by NMDA receptor-mediated LTP. J Neurosci 21:356-362.

Burgin KE, Waxham MN, Rickling S, Westgate SA, Mobley WC, Kelly PT (1990) In situ hybridization histochemistry of $\mathrm{Ca} /$ calmodulindependent protein kinase in developing rat brain. J Neurosci 10:1788-1789.

Chen YL, Huang CC, Hsu KS (2001) Time-dependent reversal of long-term potentiation by low-frequency stimulation at the hippocampal mossy fiber-CA3 synapses. J Neurosci 21:3705-3714.

Deisseroth K, Bito H, Tsien RW (1996) Signaling from synapse to nucleus: postsynaptic CREB phosphorylation during multiple forms of hippocampal synaptic plasticity. Neuron 16:89-101.

Dudek SM, Bear MF (1992) Homosynaptic LTD in area CA1 of hippocampus and effects of NMDA receptor blockade. Proc Natl Acad Sci USA 89:4363-4367.

Frey U, Morris RG (1997) Synaptic tagging and long-term potentiation. Nature 385:533-536.

Frey U, Morris RG (1998) Synaptic tagging: implications for late maintenance of hippocampal long-term potentiation. Trends Neurosci 21:181-188

Frey U, Krug M, Reymann KG, Matthies H (1988) Anisomycin, an inhibitor of protein synthesis, blocks the late phase of LTP phenomena in the hippocampal CA1 region in vitro. Brain Res 45:57-65.

Frey U, Frey S, Schollmeier F, Krug M (1996) Influence of actinomycin D, an RNA synthesis inhibitor, on long-term potentiation in rat hippocampal neurons in vivo and in vitro. J Physiol (Paris) 490:703-711.

Fujii S, Saito K, Miyakawa H, Ito K, Kato H (1991) Reversal of long-term potentiation (depotentiation) induced by tetanus stimulation of the input to CA1 neurons of guinea pig hippocampal slices. Brain Res 555:112-122.

Hawkins RD, Kandel ER, Siegelbaum SA (1993) Learning to modulate transmitter release: themes and variations in synaptic plasticity. Annu Rev Neurosci 16:625-665.

Huang CC, Hsu KS (2001) Progress in understanding the factors regulating reversibility of long-term potentiation. Rev Neurosci 12:51-68.

Huang CC, Liang YC, Hsu KS (1999) A role for extracellular adenosine in time-dependent reversal of long-term potentiation by low-frequency stimulation at hippocampal CA1 synapses. J Neurosci 19:9728-9738.

Huang CC, Liang YC, Hsu KS (2001) Characterization of the mechanism underlying the reversal of long term potentiation by low frequency stimulation at hippocampal CA1 synapses. J Biol Chem 276:48108-48117.

Huang YY, Kandel ER (1994) Recruitment of long-lasting and protein kinase A-dependent long-term potentiation in the CAl region of hippocampus requires repeated tetanization. Learn Mem 1:74-82.

Huang YY, Nguyen PV, Abel T, Kandel ER (1996) Long-lasting forms of synaptic potentiation in the mammalian hippocampus. Learn Mem 3:74-85.

Huber KM, Kayser MS, Bear MF (2000) Role for rapid dendritic protein synthesis in hippocampal mGluR-dependent long-term depression. Science 288:1254-1257.

Impey S, Mark M, Villacres EC, Poser S, Chavkin C, Storm DR (1996) Induction of CRE-mediated gene expression by stimuli that generate longlasting LTP in area CA1 of the hippocampus. Neuron 16:973-982.

Kang H, Schuman EM (1996) A requirement for local protein synthesis in neurotrophin-induced hippocampal synaptic plasticity. Science 273:1402-1406.

Krug M, Loessner B, Ott T (1984) Anisomycin blocks the late phase of LTP in the dentate gyrus of freely moving rats. Brain Res Bull 13:39-42.

Link W, Konietzko G, Kauselmann G, Krug M, Schwanke B, Frey U, Kuhl K
(1995) Somatodendritic expression of an immediate early gene is regulated by synaptic activity. Proc Natl Acad Sci USA 92:5734-5738.

Lyford GL, Yamagata K, Kaufmann WE, Barnes CA, Sanders LK, Copeland NG, Gilbert DJ, Jenkins NA, Lanahan AA, Worley PF (1995) Arc, a growth factor and activity-regulated gene, encodes a novel cytoskeletonassociated protein that is enriched in neuronal dendrites. Neuron 14:433-445.

Madison DV, Malenka RC, Nicoll RA (1991) Mechanisms underlying longterm potentiation of synaptic transmission. 14:379-397.

Martin KC, Casadio A, Zhu H, Yaping E, Rose JC, Chen M, Bailey CH, Kandel ER (1997) Synapse-specific, long-term facilitation of Aplysia sensory to motor synapses: a function for local protein synthesis in memory storage. Cell 26:927-938.

Martin S, Grimwood P, Morris RGM (2000) Synaptic plasticity and memory: an evaluation of the hypothesis. Annu Rev Neurosci 23:649-711.

Matsushita M, Tomizawa K, Moriwaki A, Li ST, Terada H, Matsui H (2001) A high-efficiency protein transduction system demonstrating the role of PKA in long-lasting long-term potentiation. J Neurosci 21:6000-6007.

Miller S, Yasuda M, Coats JK, Jones Y, Martone ME, Mayford M (2002) Disruption of dendritic translation of CaMKII-alpha impairs stabilization of synaptic plasticity and memory consolidation. Neuron 36: 507-519.

Moser EI, Krobert KA, Moser MB, Morris RGM (1998) Impaired spatial learning after saturation of long-term potentiation. Science 281:2038-2042.

Muller D, Hefft S, Figurov A (1995) Heterosynaptic interactions between LTP and LTD in CA1 hippocampal slices. Neuron 14:599-605.

Natsuki H, Izumi Y, Zarumski CF (1997) Noradrenergic regulation of synaptic plasticity in the hippocampal CA1 region. J Neurophysiol 77:3013-3020.

Nguyen PV, Kandel ER (1997) Brief theta-burst stimulation induces a transcription-dependent late phase of LTP requiring cAMP in area CA1 of the mouse hippocampus. Learn Mem 4:230-243.

Nguyen PV, Abel T, Kandel ER (1994) Requirement of a critical period of transcription for induction of late phase of LTP. Science 265:1104-1107.

O'Dell TJ, Kandel ER (1994) Low-frequency stimulation erases LTP through an NMDA receptor-mediated activation of protein phosphatases. Learn Mem 1:129-139.

Otani S, Marshall CJ, Tate WP, Goddard GV, Abraham WC (1989) Maintenance of long-term potentiation in rat dendate gyrus requires protein synthesis but not messenger RNA synthesis immediately posttetanization. Neuroscience 28:519-526.

Otmakhova NA, Lisman JE (1998) D1/D5 dopamine receptors inhibit depotentiation at CA1 synapses via cAMP dependent mechanism. J Neurosci 18:1270-1279.

Ouyang Y, Rosenstein A, Kreiman G, Schuman EM, Kennedy MB (1999) Tetanic stimulation leads to increased accumulation of $\left.\mathrm{Ca}^{2+}\right) /$ calmodulin-dependent protein kinase II via dendritic protein synthesis in hippocampal neurons. J Neurosci 19:7823-7833.

Raymond CR, Redman SJ (2002) Different calcium stores are narrowly tuned to the induction of different forms of LTP. J Neurophysiol $88: 249-255$.

Scharf MT, Woo NH, Lattal KM, Young JZ, Nguyen PV, Abel T (2002) Protein synthesis is required for the enhancement of hippocampal LTP and long-term memory by spaced training. J Neurophysiol $87: 2770-2777$

Stanton PK, Sarvey JM (1984) Blockade of long-term potentiation in rat hippocampal slices by inhibitors of protein synthesis. J Neurosci 4:3080-3088.

Staubli U, Lynch G (1990) Stable depression of potentiated synaptic responses in hippocampus with $1-5 \mathrm{~Hz}$ stimulation. Brain Res 513:113-118.

Steward O, Falk PM (1986) Protein-synthetic machinery at postsynaptic sites during synaptogenesis: a quantitative study of the association between polyribosomes and developing synapses. J Neurosci 6:412-423.

Steward O, Falk PM (1991) Selective localization of polyribosomes beneath developing synapses: a quantitative analysis of the relationships between polyribosomes and developing synapses in the hippocampus and dentate gyrus. J Comp Neurol 314:545-557.

Steward O, Levy WB (1982) Preferential localization of polyribosomes un- 
der the base of dendritic spines in granule cells of the dentate gyrus. J Neurosci 2:284-291.

Steward O, Schuman EM (2001) Protein synthesis at synaptic sites on dendrites. Annu Rev Neurosci 24:299-325.

Steward O, Wallace CS, Lyford GL, Worley PF (1998) Synaptic activation causes the mRNA for the IEG Arc to localize selectively near activated postsynaptic sites on dendrites. Neuron 21:741-751.

Tang SJ, Reis G, Kang H, Gingras AC, Sonenberg N, Schuman EM (2002) A rampamycin-sensitive signaling pathway contributes to long-term synaptic plasticity in the hippocampus. Proc Natl Acad Sci USA 99:467-472.

Torre ER, Steward O (1992) Demonstration of local protein synthesis within dendrites using a new cell culture system that permits the isolation of living axons and dendrites from their cell bodies. J Neurosci 12:762-772.

Winder DG, Mansuy IM, Osman M, Moallem TM, Kandel ER (1998) Genetic and pharmacological evidence for a novel, intermediate phase of long-term potentiation suppressed by calcineurin. Cell 92:25-37.

Woo NH, Nguyen PV (2002) "Silent" metaplasticity of the late phase of long-term potentiation requires protein phosphatases. Learn Mem 9:202-213.

Ying SW, Futter M, Rosenblum K, Webber MJ, Hunt SP, Bliss TV, Bramham CR (2002) Brain-derived neurotrophic factor induces long-term potentiation in intact adult hippocampus: requirement for ERK activation coupled to CREB and upregulation of Arc synthesis. J Neurosci 22:1532-1540. 